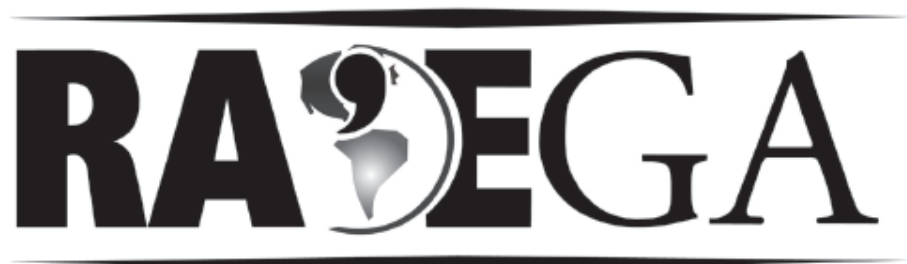

O ESPAÇO GEOGRÁFICO EM ANÁLISE

\title{
JÚLIO DE CASTILHOS/RS: A CADEIA PRODUTIVA DA SOJA COMO AGENTE REORGANIZADOR DO SEU ESPAÇO AGRÁRIO.
}

\section{JÚLIO DE CASTILHOS/RS: THE PRODUCTION CHAIN OF SOY AS A REORGANIZING AGENT OF ITS AGRARIAN SPACE}

\author{
Monica Cargnin ${ }^{1}$ \\ Meri Lourdes Bezzi ${ }^{2}$
}

\section{RESUMO}

A organização espacial de Júlio de Castilhos/RS, desde sua gênese, está atrelada à distribuição de terras, através de sesmarias. Este fato foi responsável por sua estrutura econômica. Nessa perspectiva, a pesquisa centra-se na abordagem do espaço agropecuário de Júlio de Castilhos frente a novos atores econômicos. Como objetivo primordial o trabalho visa compreender a dinâmica socioeconômica a partir da introdução da cadeia produtiva da soja. Para a análise dos resultados, combinaram-se técnicas de coleta de dados qualitativos e quantitativos de fontes primárias e secundárias.

\footnotetext{
1 Mestre em Geografia pelo Programa de Pós-graduação em Geografia e Geociências/NERA/CCNE/UFSM; monicacargnin@yahoo.com.br.

2 Orientadora - Profa. Dra. do Programa de Pós-graduação em Geografia e Geociências/NERA/CCNE/UFSM, meri@oslo.ccne.ufsm.br.
} 
Como consideração final destaca-se que a pecuária está cedendo áreas via processo de despecuarização espacial para a lavoura da soja, sendo responsável por novos arranjos produtivos no município.

Palavras-chave: espaço agrário; lavoura empresarial da soja; organização do espaço; modernização da agricultura.

\section{ABSTRACT}

The spatial organization of Julio de Castilhos / RS, since its genesis is tied to the distribution of land through grants. This fact was responsible for the city economic structure. From this perspective, the research focuses on agricultural exploration of the space in Julio de Castilhos, facing new economic actors. As the main goal, the work aims to understand the social and economic dynamics from the introduction of the soy production chain. For the analysis of results, combined techniques were used for collecting qualitative and quantitative data from primary and secondary sources. And as a final consideration, it is emphasized that the livestock areas are giving away space for other crops, accounting for new production arrangements in the county.

Key words: Agricultural space; corporate farming of soybeans; spatial organization; modernization of agriculture.

\section{INTRODUÇÃO}

$\mathrm{Na}$ atualidade, no Rio Grande dos Sul, os investimentos em tecnologias e capital, na agricultura e o seu direcionamento para as culturas voltadas para o mercado externo as tornaram bastante viáveis e lucrativas. Considerando a pecuária tradicional o processo de modernização ocorreu de forma lenta e gradativa através do melhoramento do rebanho. Nesse sentido, a agricultura desenvolvida em moldes empresariais, pressiona as áreas de pecuária, na forma de arrendamento dos campos, originando novos arranjos espaciais impondo, consequentemente, transformações também no espaço urbano.

Nesse contexto, a pesquisa elegeu como objeto de estudo o município de Júlio de Castilhos/RS, tendo como preocupação primordial analisar a dinâmica socioeconômica a partir da introdução da cadeia produtiva da soja na organização/reorganização espacial desse recorte espacial. Especificamente o trabalho buscou: (a) identificar e analisar o marco temporal da inserção da cultura da soja e a sua evolução na ocupação do espaço agrícola do município 
e, (b) verificar a relação existente entre o processo de despecuarização espacial e as novas relações que a cadeia produtiva da soja impõe na unidade territorial em estudo.

O contexto histórico de formação de Júlio de Castilhos está atrelado à distribuição de terras, através da doação de sesmarias. Portanto, apresenta características típicas desse período, ou seja, a matriz tradicional, baseada na pecuária extensiva com predomínio da grande propriedade. No entanto, a partir da década de 80 a pecuária está cedendo espaço não apenas em termos de produção, mas, também, em área, uma vez que o mesmo está sendo transferido para a agricultura gradativamente. Assim, o setor agrário se redesenha, pois as áreas de campo nativo transformaram-se em terras para a lavoura comercial da soja. Através dessa nova cadeia produtiva, o município busca perspectivas de desenvolvimento local/regional e, consequentemente, a sua inserção no mercado externo.

É importante destacar que a cultura da soja começou a ser cultivada, no Estado gaúcho, em áreas de planalto, no qual se localiza Júlio de Castilhos. As potencialidades naturais como a presença de uma topografia com relevo plano e solos férteis, além de chuvas bem distribuídas o ano todo aliado ao econômico, ou seja, a valorização do grão no mercado internacional contribuiu para a expansão da soja em todo o Rio Grande do Sul.

Tendo como base a matriz teórica, delineou-se a parte prática da pesquisa a qual foi desenvolvida através de etapas. A primeira esteve relacionada à coleta de dados provenientes de fontes secundárias, como dados censitários obtidos no Instituto Brasileiro de Geografia e Estatística (IBGE) e na Fundação de Economia e Estatística (FEE) referentes aos dados ligados à agropecuária de Júlio de Castilhos.

A segunda forma de obtenção dos dados foi a coleta dos mesmos através da pesquisa de campo. Essa foi realizada nos meses de julho e agosto de 2008, tendo como população alvo 50 produtores rurais do município. Esses foram pré-selecionados conforme o total de estabelecimentos agropecuários existentes no município, de acordo com censo agropecuário do IBGE. 
Os critérios para a seleção dos agropecuaristas entrevistados foram definidos através de amostra intencional, abrangendo todos os distritos do Município. Para a seleção dos estabelecimentos agropecuários, foram consideradas as atividades praticadas pelos mesmos, ou seja: 1) pecuaristas; 2) agricultores e, 3) pecuaristas e agricultores.

Dessa forma, os dados coletados subsidiaram a pesquisa a qual tinha como fio condutor analisar as transformações espaciais decorrentes da inserção da cadeia produtiva da soja e sua relação com outras atividades econômicas do município. Nesse sentido, as variáveis selecionadas para o trabalho, no que diz respeito à agricultura, foram à cultura da soja, do trigo, do milho. E, para a pecuária, o número de bovinos e de ovinos. Investigou-se, também, alguns componentes da cadeia produtiva da soja como a questão do armazenamento através dos silos; a infra-estrutura da malha viária através dos transportes e estradas pavimentadas ou não; o armazenamento dos produtos através das cooperativas; a modernização via maquinários e insumos agrícolas e as tecnologias empregadas, entre outros elementos importantes para viabilizar essa cadeia produtiva.

\section{REVISITANDO AS MATRIZES TEÓRICAS}

\section{1 A influência da modernização da agricultura na organização socioespacial do Estado gaúcho}

O espaço agropecuário do Rio Grande do Sul historicamente foi configurado estruturalmente em três formas de organização diferenciadas: a pecuária tradicional, a agropecuária colonial e a lavoura empresarial, no qual a modernização ocorreu de forma distinta nos três segmentos produtivos (FEE, 1978).

O setor primário do Estado gaúcho tem sua gênese na pecuária extensiva. No decorrer do tempo esta atividade foi sendo fragilizada, principalmente, pela falta de apoio econômico através de financiamentos, pois 
esses eram quase que exclusivamente destinados para a agricultura. Com o crescimento do setor agrícola, possibilitado pela modernização, iniciada na década de 1970, alterou-se nos municípios gaúchos, esse cenário no meio rural.

A inserção das inovações tecnológicas na agricultura, e a entrada maciça de capital, através dos financiamentos, imprimiram uma nova dinâmica no meio rural. Para os pecuaristas, a presença da agricultura, em áreas até então de pecuária tradicional, foi uma alternativa para a crise que se fazia presente nesse setor. Assim, a adesão ao capitalismo rural, via agricultura, através da inserção de culturas capitalistas como a da soja realizada, na sua maior parte, em terras arredadas, apresentava-se como uma saída viável (BEZZI, 1985).

Pode dizer-se, então, que foi através do arrendamento de terras que a lavoura empresarial adentrou em áreas anteriormente destinadas à pecuária. Paralelamente, possibilitou a modernização da agricultura através da nova cadeia produtiva da soja.

Ressalta-se que a lavoura empresarial já ocupava áreas da pecuária, desde a década de 1950. No entanto, a intensificação do processo de modernização agrícola, se fez sentir, de forma mais intensa, na década de 1970. Como menciona Pesavento (1980, p. 74) "A ocupação dos latifúndios pecuaristas pela lavoura já era assinalada em 1917". Tal sistemática possibilitava, ao pecuarista, manter em seu poder o título da propriedade descentralizando apenas a produção via agricultura, ou seja, o "status quo" da pecuária foi mantido.

Ainda que a modernização da agricultura no Estado tenha se iniciado com o arroz, na década de 1920, foi através do trigo que se concretizou a verdadeira revolução agrícola, na qual a mecanização se inseriu no setor agrícola em ritmo acelerado.

No entanto, em meados da década de 1960, a atividade tritícola apresentou decréscimo na sua produção, devido à disseminação da "ferrugem", doença que reduz a qualidade e o rendimento de grãos, e a concorrência de preços pelo trigo importado da Argentina, Uruguai, Estados 
Unidos e Canadá, passando a disponibilizar um grande número de máquinas e terras ociosas (CONCEIÇÃO, 1984; BEZZI, 1985; BRUM, 1988). Com a decadência parcial do plantio de trigo, cultivado nos meses de inverno, a soja, cultura de verão, passou a utilizar as terras e maquinários ociosos. Consolidando-se então, o binômio trigo-soja como a melhor alternativa econômica no estado, o qual foi decisivo para o crescimento da lavoura empresarial gaúcha.

A modernização da agricultura baseada na intensa utilização de máquinas e insumos agrícolas permitiu o surgimento da lavoura empresarial. Através dela a cultura da soja passou a desempenhar importante função para a economia gaúcha, pois com

\footnotetext{
A crescente demanda por essa cultura, principalmente a partir de 1968, estimulou o incremento da produção desse produto, fazendo com que o Estado cumprisse a função de geradora de divisas no processo global de acumulação, mediante a exportação desse grão (BEZZI, 1985, p. 28).
}

Foi através da lavoura empresarial com sua produção desenvolvida em grandes áreas que a cultura da soja se inseriu no mercado nacional e conquistou importância econômica.

\section{2 A expansão do trigo e da soja através da lavoura empresarial}

O desenvolvimento da agricultura, no decorrer do tempo, passou por diversas etapas. Pode dizer-se que houve momentos de expansão e outros de retração ligados a fatores internos e externos (clima, exigências do mercado, preço do dólar, entre outros) que influenciaram direta ou indiretamente no setor primário gaúcho.

Nesse sentido, o setor agrícola passou a absorver a revolução tecnológica de forma limitada. Assim, a agricultura tradicional transformou-se gradativamente em agricultura moderna. Salienta-se que a agricultura tradicional consistia na utilização intensa da fertilidade natural do solo e do uso de mão-de-obra familiar, ao passo que a agricultura moderna aplica o uso 
intensivo de máquinas, implementos, equipamentos, técnicas sofisticadas e insumos modernos (BRUM, 1988).

No entanto, a partir de 1956 que em decorrência da mudança do padrão de acumulação no Estado, período marcado pela estagnação, descapitalização e retrocesso do setor rural, no qual a agricultura passou a absorver as tecnologias produzidas via setor industrial. Esse retrocesso foi mais intenso na produção de trigo, tornando-o menos participativo, como poupador de divisas. Dessa forma, com a decadência parcial do trigo, a lavoura da soja passou a desempenhar papel fundamental como geradora de divisas na agricultura gaúcha. A cultura da soja incorporou as tecnologias utilizadas na lavoura de trigo, bem como, aproveitou os mesmos solos e os mesmos equipamentos. Esses fatores favoreceram a retomada no processo de desenvolvimento na agricultura. Foi então através do binômio trigo/soja que a lavoura empresarial conquistou um significativo avanço no Estado gaúcho (BEZZI, 1985).

A cultura da soja expandiu-se rapidamente por aproveitar a infraestrutura e os recursos técnicos disponibilizados pela lavoura de trigo. A leguminosa já vinha sendo plantada, no Rio Grande do Sul, em pequena escala, mas foi na década de $70 \mathrm{com}$ a disponibilidade de financiamentos, seja através de bancos públicos ou privados e devido à cotação favorável dos preços internacionais do produto, é que tem início o ciclo expansivo mais significativo dessa cultura (HEIDRICH, 2000).

É importante destacar que "[...] a soja, até a primeira década de 1960, era cultivada em áreas de pequena propriedade familiar, com inexpressiva participação em termos de agricultura estadual" (FEE, 1979, p. 73). A soja passa a ter valor comercial, na medida em que se descobre sua importância econômica principalmente para o mercado externo. Paralelamente, ela é utilizada para alimentação animal, e através do óleo na substituição da gordura animal na alimentação humana. Desse modo, a substituição das gorduras animais pelas vegetais foi o primeiro incentivo de mercado para essa cultura (FEE, 1979).

Desde o início, a produção da soja o Estado gaúcho, se enquadrou no padrão americano, desta forma 
Insere-se no Rio Grande do Sul, o aparecimento da soja como principal cultura de exportação, obtendo de 1950 a 1975 um extraordinário crescimento tanto em valor de produção como em quantidade produzida e área cultivada (CONCEIÇÃO, 1984, p. 8).

O plantio de soja já se inseria no espaço agrário gaúcho nos moldes tecnológicos americano, com produção predominantemente voltada para a exportação.

A grande produção agrícola, principalmente a de soja, esteve vinculada ao incremento da tecnologia à agricultura, denominada de "Revolução Verde", ocorrida na década de 1950. A esse respeito Bombardieri (2000, p. 44) assinase que

\footnotetext{
Os Estados Unidos começaram a exportar para os países de Terceiro Mundo um "pacote tecnológico" para a agricultura. O modelo propunha a transferência de tecnologia agrícola para estes países, com a promessa de aumentar os rendimentos e reduzir os índices de pobreza nestas regiões. Estes "pacotes" eram constituídos, por variedades de plantas altamente produtivas, utilização de máquinas equipamentos específicos e especializados e de pesticidas químicos e insumos em sua maioria derivados de petróleo.
}

Com base nessas reflexões, pode-se afirmar que a produção de soja através da utilização massiça de implementos agrícolas, foi responsável pela expansão dessa cultura e foi um fator decisivo para a modernização agrícola e, consequentemente, viabilizou o desenvolvimento local/regional (CARRION JÚNIOR, 1981).

No que se refere ao processo de expansão da soja enfatiza-se que nas décadas de1970 e 80, o crescimento da produção dessa cultura esteve vinculado à política governamental, ao estimular a expansão do grão, considerado o carro chefe para o desenvolvimento econômico, juntamente com a ampliação de empreendimentos industriais (BEZZI, 1985 e BELLINASO, 2002). 
Acrescenta-se que, a produção de soja insere-se nos novos moldes tecnológicos, com a técnica do plantio direto na palha, cujo sistema foi importante para a conservação do solo com diminuição da erosão nas lavouras. Essa técnica, que visa favorecer uma forma de plantio de algumas culturas e, a preservação do solo, pode contribuir também para o aumento da germinação de plantas invasoras, que são indesejáveis, tornando-se um problema do ponto de vista econômico. Para controlar a disseminação dessas plantas, o agricultor faz uso de herbicidas e, quando utilizado em excesso pode desencadear sérios problemas de saúde pública e ambiental (EMBRAPA CLIMA TEMPERADO, 2006).

As novas necessidades da demanda do mercado, através da produção em grande escala para a exportação levaram à segunda Revolução Verde. A biotecnologia das plantas geneticamente modificadas, através das sementes transgênicas, provocou, de certa forma, uma revolução no setor agrícola do Brasil. Com a introdução dessas sementes, via soja transgênica, foi possível diminuir o custo da produção através da redução de tipos de agrotóxicos utilizados na lavoura (BENETTI, 2000).

Apesar dos benefícios que os transgênicos trouxeram para 0 desenvolvimento da atividade agrícola, também tornou o produtor rural dependente das multinacionais que detém a tecnologia para produção das sementes, conforme destaca Hespanhol (2007, p.193)

\footnotetext{
A biotecnologia tem se constituído numa alternativa para ampliar os níveis de produtividade dos produtos agropecuários e reduzir custos. Ela provoca, porém, a ampliação da dependência dos produtores rurais em relação às empresas multinacionais que controlam a produção de sementes geneticamente modificadas. A baixa margem de lucro por unidade produzida e o elevado custo das novas tecnologias têm levado ao crescimento da escala de produção e inviabilização a exploração de commodities em pequenas áreas.
}

A produção da soja transgênica, para ser viável, ao produtor rural, deve ser desenvolvida em grandes áreas. No Rio Grande do Sul tal fato tem 
pressionado para que essa lavoura seja predominante nos médios e grandes estabelecimentos.

A soja encontra-se, na atualidade, como um commodity importante na pauta das exportações brasileiras, além do grande consumo no mercado interno, seja, na forma industrializada, através da extração de óleos, margarina e biodiesel, ou na comercialização de grãos para ração, sementes, entre outras formas de obtenção de produtos dessa leguminosa.

\subsection{A dinâmica do Complexo Agroindustrial da soja}

Nas últimas décadas a agricultura brasileira passou por significativas reestruturações, no que se refere às atividades agrícolas, alterando o modo de produzir e organizar os mercados. Com a evolução da economia através do capitalismo, mudou a organização do espaço agropecuário para um processo mais dinâmico determinado pelos Complexos Agroindustriais (CAls). A instalação dos CAls favoreceu a expansão e a modernização da lavoura empresarial da soja no estado gaúcho e no município em análise.

Considerando o processo de vinculação da agricultura ao CAI, pode-se verificar uma indústria voltada para a agricultura, fornecendo insumos e maquinários agrícolas. Paralelamente, desenvolve-se uma agroindústria, na qual a agricultura passa a ser fornecedora de matéria-prima.

No contexto da organização do Complexo Agroindustrial, a agropecuária capitalista apresenta-se dependente da indústria em dois sentidos. De um lado, o setor agropecuário encontra-se subordinado às indústrias que produzem os elementos básicos para o seu desenvolvimento, de outro, as indústrias de beneficiamento e empresas de comercialização, as quais controlam os preços pagos aos produtos para os produtores agrícolas.

O novo padrão de organização das atividades no setor agrário, a cultura da soja se insere, consolidando o "complexo soja" o qual se concretizou na década de 70. De acordo com Mazzali (2000, p. 67) 
o "[...] complexo soja foi favorecido por dois grandes fatores [...] a) a presença de uma conjuntura internacional extremamente favorável e, b) a intervenção marcante do Estado em todas as fases da cadeia produtiva da soja".

Foi também a cultura da soja a principal responsável pela introdução do conceito de agronegócio, no contexto nacional. Para o agronegócio da soja é necessária uma infra-estrutura composta, pelos serviços de apoio que apresentam conexão com o agricultor. Esses são os serviços agronômicos, pesquisa e desenvolvimento (P\&D), os serviços bancários, marketing, vendas, transporte (via rodovias, ferrovias e hidrovias), armazéns através das cooperativas ou empresas cerealistas particulares, os portos necessários para o escoamento da exportação de grãos, assistência técnica, bolsa de valores que direciona o agronegócio da soja, entre outros serviços.

As cooperativas, em especial, passaram a atuar no ramo do agronegócio como um facilitador no processo de industrialização do rural, tanto da sua produção agrícola quanto do fornecimento de sementes, fertilizantes e defensivos. Elas também seriam as principais responsáveis pela implantação da infra-estrutura de armazenagem, transportes e comercialização da produção (HEIDRICH, 2000).

Atualmente, a integração indústria-produtor de soja está em processo de crescimento, favorecida pelas descobertas da ciência relacionada à utilidade do óleo da soja, dentre elas a produção do biodiesel. Este, após processos de beneficiamento é adicionado ao combustível tradicional usado nos transportes e maquinários agrícolas, o qual está se destacando entre os recursos renováveis. O biodiesel veio fortalecer o mercado para a produção da soja, que está cada vez mais, valorizado entre as commodities brasileiras. $\mathrm{O}$ fator preço da saca de soja faz com que os produtores reorganizem seus espaços produtivos substituindo, em parte, outros cultivos agrícolas pela soja, ou ampliando o plantio para novas áreas destinadas principalmente à criação de gado de corte. 


\section{Agropecuária de Júlio de Castilhos e as transformações decorrentes da origem e expansão da lavoura empresarial da soja}

A organização do espaço produtivo agropecuário ocorre geralmente impulsionada por um conjunto de elementos e de fatores históricos e socioeconômicos, os quais fazem parte de um conjunto de atividades que contribuem para o desenvolvimento desse segmento. Paralelamente, os fatores políticos e econômicos pautados pelo mercado internacional, interferem direta ou indiretamente na estruturação da agropecuária enquanto atividade econômica.

Esses fatores refletem-se no setor primário e, por vezes, o direcionam, exercendo importante papel no processo de decisão dos agropecuaristas, no que diz respeito, a escolha do tipo de atividade a serem priorizadas nos seus investimentos, ou seja, se na agricultura ou na pecuária.

O município de Júlio de Castilhos em relação à sua estrutura fundiária historicamente foi organizado através dos grandes estabelecimentos agropecuários, tendo como atividade tradicional a pecuária. Da sua gênese, através da distribuição das sesmarias, até a atualidade, o município passou por transformações e/ou reorganizações no que se refere ao tamanho das propriedades e os tipos de atividades praticadas nas mesmas.

Com relação ao tamanho dos estabelecimentos agropecuários dos cinquenta produtores entrevistados, quinze estabelecimentos, ou seja, 30\% estão classificados nos grupos de área total, que variam de 500 a 2500 ha e, $64 \%$, possuem estabelecimentos rurais com áreas menores de 500 ha. Esses dados demonstram que houve uma reorganização na estrutura fundiária dos estabelecimentos agropecuários, considerando a origem histórica de concentração de terras no município. Tal fato é consequência da diminuição da área destinada à pecuária devido à expansão da lavoura empresarial da soja. Essa situação forçou a fragmentação parcial da dimensão dos estabelecimentos agropecuários, pois alguns proprietários arrendam parte de suas terras para as lavouras temporárias. 
Aliado também a estes fatores, o município foi alvo de pressões dos movimentos sociais como o MST (Movimento dos Trabalhadores Sem Terra), os quais lutam pelo acesso e pelo cumprimento da função social da terra. Buscando atender em parte, a essas reivindicações, foram criados três assentamentos em Júlio de Castilhos, os quais foram responsáveis, em parte, pela fragmentação da dimensão dos mesmos.

Os motivos da reorganização da estrutura fundiária são diversos. Considera-se, desde a expansão dos estabelecimentos através da compra de áreas próximas devido ao esgotamento da fronteira agrícola no Estado gaúcho, até a sua utilização para o pagamento de dívidas contraídas através de investimentos ou financiamentos realizados como forma de permanecerem na atividade agropecuária.

A maioria dos pecuaristas castilhenses, para se manterem na atividade, procura estabelecer novas formas de utilização das terras de seus estabelecimentos com 0 intuito de maximizar os rendimentos. Uma das alternativas é o arrendamento e/ou parceria na lavoura temporária da soja, geralmente no período de verão. No inverno, alguns proprietários utilizam a lavoura com pastagem para concluir o processo de engorda dos bovinos sendo essa sistemática bastante utilizada, pois ela acelera o ciclo da pecuária.

Destaca-se também que dos entrevistados, a parceria na agricultura foi constatada em apenas um estabelecimento agropecuário, correspondendo a essa forma de condição de trabalho com $25 \%$ da utilização da lavoura temporária para soja na propriedade. Cabe ressaltar que, dos estabelecimentos agropecuários com pecuária, três produtores rurais não trabalham diretamente com a atividade agrícola, somente com pecuária, sendo que suas lavouras são arrendadas para terceiros nos meses de verão. Além disso, cinco estabelecimentos trabalham somente com pecuária de invernada, ou seja, de engorda do gado, apenas no período de inverno em áreas de lavoura temporária. E, seis entrevistados não possuem pecuária em suas propriedades, realizando apenas atividades agrícolas.

Ocorreu uma inversão no percentual do grau de utilização das terras de acordo com a condição do declarante e do tipo de atividade, ou seja, a 
agricultura esteve presente na maior parte dos estabelecimentos agropecuários e ocupou os maiores percentuais de área.

Os maiores percentuais para a lavoura cultivada encontravam-se nos grupos de área total entre 60 a $80 \%$ e 80 a 100\% da utilização da área do estabelecimento agropecuário para a agricultura. Isto significa que a lavoura temporária estava presente na maior parte dos estabelecimentos de Júlio de Castilhos e, do mesmo modo, predominavam as lavouras cultivadas pelos proprietários. Em contrapartida, para os estabelecimentos que realizam a pecuária, seja em campo nativo ou, em áreas de lavoura em determinada época do ano, o maior número, quatorze estão nos grupos de área total de menor grau de utilização da área, ou seja, entre 0 a $20 \%$ da propriedade e se destinam para a atividade da pecuária.

Percebe-se que houve uma diminuição das áreas destinadas para a pecuária em consequência do aumento gradual das lavouras, as quais pressionaram as áreas de campo nativo. Tal expansão se tornou possível devido às potencialidades físico/natural, através do relevo favorável, o qual possibilitou a inserção da mecanização na maior parte do município. Há que se considerar, também, o total de onze estabelecimentos agropecuários, nos quais a lavoura é cultivada pelo arrendatário nos meses de verão e, no inverno, a exploração da mesma retorna para o proprietário, o qual as utiliza para engorda do gado. Esta é uma prática que está se tornando comum no município.

Se por um lado, a exploração do estabelecimento agropecuário era realizada, na maior parte pelos proprietários, por outro, o local de residência da maioria desses, não é a sede da propriedade na zona rural, pois em muitos casos, os proprietários residem em outros municípios. Essa dinâmica iniciou-se com os fazendeiros e acentuou-se com os empresários rurais da soja. Dessa forma, o espaço urbano também se alterou, pois é frequente a busca por moradias, na cidade, para alugar, ou, então, para construção de casas próprias. Percebe-se, que essa nova reestruturação produtiva alterou o design urbano, pois se visualiza, no espaço urbano do município, a expansão do mercado imobiliário. 
Atualmente, a agropecuária em Júlio de Castilhos é organizada e administrada de maneiras distintas. Além do proprietário, o arrendatário também passou a explorar a atividade agropecuária e, em alguns casos, a administrar o estabelecimento.

As áreas exploradas por produtores rurais, através do arrendamento de terra apresentam dimensões que variam de 50 a 1500 ha. Dos entrevistados que são arrendatários 94\%, declararam que essas áreas são destinadas para a lavoura comercial de soja no período de verão e, no inverno, utilizadas com outras culturas. Assim, tem-se para cada período, duas situações distintas. $O$ arrendatário planta trigo e aveia e/ou azevém para a obtenção de sementes no inverno. Ou, a lavoura após a semeadura da aveia ou azevém ou ambas, é devolvida ao proprietário para realizar a pecuária de engorda. Tal sistemática visa ampliar o retorno econômico através da redução de custos.

Salienta-se que apenas $6 \%$ dos entrevistados utilizavam terra arrendada para a pecuária na modalidade campo. As dimensões de área para essa modalidade de atividade variam de 200 a 500 ha e são destinados, para abrigar o gado no período de verão aguardando novamente a pastagem da lavoura no inverno. Para comportar o grande plantel bovino em áreas de campo, sem prejudicar a produção do rebanho, o pecuarista tem investido na melhoria das pastagens no campo nativo, o qual passou a ser trabalhado de forma mais intensiva.

É importante destacar que houve a valorização da terra em consequência da expansão da lavoura empresarial da soja, visando à demanda no mercado nacional e internacional. Isso repercutiu nos valores atribuídos ao hectare de área para compra e, também, para o arrendamento.

No que diz respeito à presença das cooperativas, no município, essas exercem papel fundamental para a agropecuária e para a economia local. Enfatiza-se que a maioria dos entrevistados é sócio de uma ou mais cooperativa. Entre elas destacam-se as cooperativas e empresas agropecuárias de capital privado como: a Cooperativa Agropecuária Júlio Castilhos (COTRIJUC); a Cooperativa Agrícola Mista Nova Palma (CAMNPAL); a Cooperativa Tritícola de ljuí (COTRIJUÍ); a Cooperativa Agrícola Mista 
General Osório (COTRIBÁ); o Sistema de Crédito Cooperativo (SICREDI); a Cooperativa Agrícola Tupanciretã (Agropan); e a Agropecuária de recebimento de grãos (Agrodeltha). As cooperativas exercem papel decisivo no processo de armazenamento e industrialização dos grãos produzidos.

A lavoura consorciada com a pecuária estava presente em $90 \%$ dos estabelecimentos agropecuários de Júlio de Castilhos. Destaca-se que apenas $10 \%$ dos proprietários praticam a agricultura anualmente com culturas e em épocas distintas. Dos estabelecimentos com presença da pecuária consorciada com agricultura obteve-se um grande percentual desses, em que a pecuária ocorre apenas na entressafra da lavoura de soja, ou seja, no período de inverno onde estão plantadas as pastagens (TRABALHO DE CAMPO, 2008).

Os motivos pela opção de consorciar a pecuária com a agricultura derivam principalmente dos benefícios econômicos dessa prática. Dentre as razões apresentadas pelos entrevistados pode-se destacar que essa sistemática visa à complementação e garantia de renda nas atividades agropecuárias, ou seja, uma atividade complementa a outra. Paralelamente, ocorre o melhor aproveitamento da propriedade, pois o relevo permite a existência de áreas agricultáveis e outras não. Esta integração possibilita, também, a diminuição dos custos com os equipamentos e torna o uso mais intensivo da mão-de-obra, além de acelerar o ciclo da pecuária, uma vez que se faz o uso da pastagem plantada.

Para os estabelecimentos que optaram em realizar somente agricultura esses, o fazem por considerarem que a pecuária está se tornando inviável economicamente. Entre os fatores decisivos que levaram muitos produtores a se dedicarem somente à prática agrícola estão a fertilidade do solo e a não compactação do mesmo, devido as técnicas usadas tornando-o mais produtivo.

O município, por um longo período, teve na atividade pecuarista com base na criação de gado bovino de forma extensiva, com ciclo completo, a principal atividade econômica. Essa prática modificou-se com o avanço das lavouras temporárias. O consórcio da lavoura com a pecuária é uma possibilidade que visa à aceleração do ciclo da pecuária. No entanto, tem sido uma prática cada vez menos aceita pelos agricultores, pois dependendo do 
grau de utilização da lavoura pela pecuária, ocorre a compactação do solo. No entanto, para se inserir no mercado, a pecuária, busca alternativas mais modernas de produção como o cruzamento com novas raças e melhoramento da alimentação dos animais com pastagens provenientes da lavoura nos períodos de entressafra ou do próprio campo nativo.

Para se compreender a evolução do efetivo da pecuária de Júlio de Castilhos buscou-se resgatar fatos que ocorreram no decorrer da escala temporal selecionada, ou seja, no período de 1940 a 2006. Dentre eles, destaca-se que as sucessivas crises econômicas ocorridas a partir da década de 30, levaram ao fechamento e falência de diversos frigoríficos. Esse fato gerou crise nesse setor econômico, a qual refletiu gradativamente na atividade pecuarista, levando a diminuição da criação de gado da década de 40 a 60 (Figura 1).

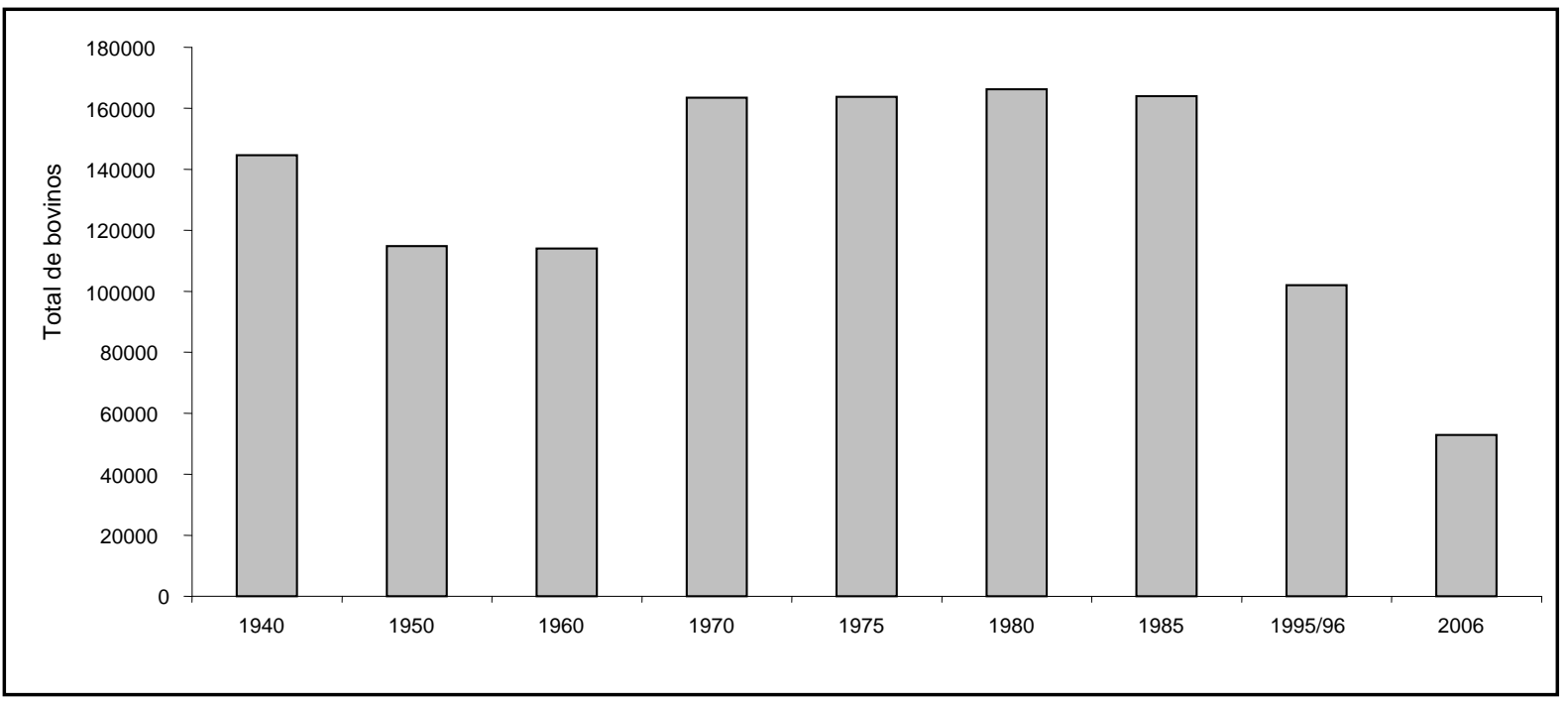

Figura 1 - Gráfico do efetivo de bovinos no município de Júlio de Castilhos/RS no período de 1940 a 2006.

Fonte: Censo econômico do IBGE de 1940, censo agrícola de 1950 e 1960, censo agropecuário de 1970, 1975, 1980, 1985, 1995/96 e 2006.

Org.: CARGNIN, M., 2008.

Observando-se a figura 1, a partir da década de 1970 percebe-se que a pecuária apresenta recuperação, pois sua produção aumenta em relação à 
década de 1960, apresentando-se praticamente constante até 1985. Atribui-se a esse crescimento e posterior estabilização da pecuária local, proporcionado pelo crescimento do mercado da carne, bem como, a maior oferta de pastagens aos bovinos disponibilizadas pela lavoura temporária em expansão, apesar da diminuição da área com campo nativo. A partir de 1985 a pecuária de bovinos diminuiu o seu efetivo. Tal fato é reflexo das oscilações do preço do boi vivo, aliado, ao surto de febre aftosa que tem afetado o mercado da carne no Brasil e no exterior. Acrescenta-se, também, que a valorização da soja no mercado internacional favoreceu a expansão das áreas de agricultura sobre as áreas de campo nativo forçando a diminuição da pecuária e/ou sua reestruturação espacial.

Nesse contexto, a lavoura de soja tem seu início, em meados da década de 1960, quando foram registrados os primeiros dados em relação à produção do grão, em Júlio de Castilhos. Assim, a década de 1960 configura-se como o marco da inserção da cultura da soja comercial no município. No entanto, isso não significa que anterior a esse período ela não se fazia presente, pois já era realizado o plantio dessa leguminosa para a alimentação de animais e, em algumas lavouras a mesma era plantada em caráter experimental.

Buscando incentivar o desenvolvimento dessa cultura, em escala local, a Fundação Estadual de Pesquisa Agropecuária (FEPAGRO), na década de 1950, começou pesquisar variedades de soja que fossem adequadas às condições edáficas do Município. Dessa forma, as primeiras lavouras de soja foram inseridas pela FEPAGRO, a qual procurava incentivar os proprietários a plantar a mesma buscando diversificar a produção agrícola que se consolidava através do trigo, cultura característica de inverno. Tal fato tornaria a atividade agrícola mais rentável e atraente para os agricultores. A soja que se expandia, no mercado externo, passou a despertar interesse dos agricultores. Além disso, a topografia do município propiciava a mecanização dessa lavoura. Consolidava-se, assim, o binômio trigo/soja. Nesse sentido, o produtor tinha o aproveitamento anual de suas terras, destinando-as a soja, no verão e, no inverno, ao trigo. 
A expansão ou redução das áreas da cultura temporária de soja estão ligadas aos condicionantes climáticos e de mercados. É importante assinalar que a atividade agrícola é vulnerável a uma série de fatores, os quais podem favorecer ou dificultar o seu desenvolvimento. Entre eles citam-se: as alterações nas condições do tempo, a oscilação dos preços no mercado e a proliferação de pragas. A interferência do tempo ocorre de forma bastante intensa manifestando-se através das secas ou excesso de chuvas, considerando que esses fatores são decisivos na quantidade e qualidade da produção agrícola.

A Figura 2, demonstra a evolução, dessa cultura no município. Para o período de 1960 a 1980 tem-se uma produtividade que varia de 16 a 25 sacas de soja por hectare. A partir de 1985 há um aumento da produção, chegando à produtividade de 30 sacas por hectare. $O$ incremento na produtividade, após 1985, deve-se a inserção do plantio direto, o qual diminui as perdas da camada de solo agricultável, aumentando a sua fertilidade e, consequentemente, proporciona maior produção.

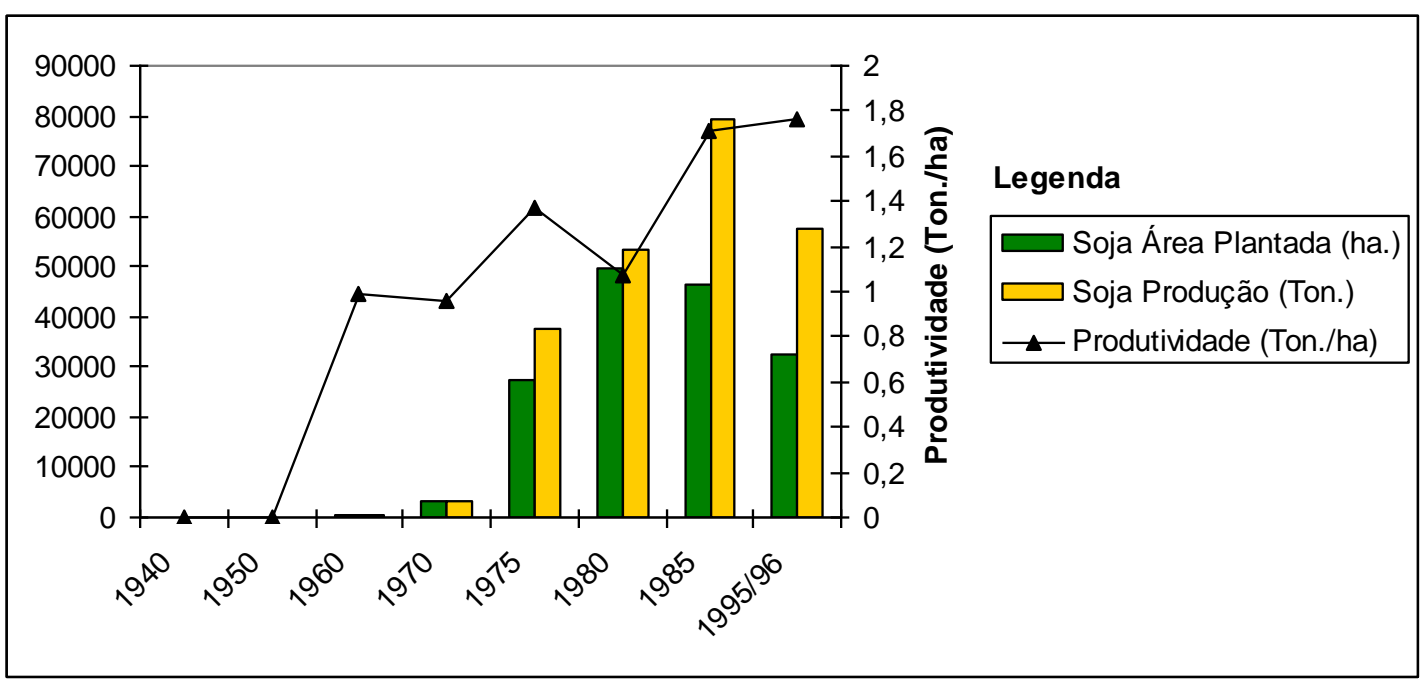

Figura 2 - Gráfico da evolução da área plantada e produção de soja no município de Júlio de Castilhos/RS.

Fonte: Censo econômico do IBGE de 1940, Censo Agrícola de 1950 e 1960, Censo Agropecuário de 1970, 1975, 1980, 1985 e 1995/96.

Org.: CARGNIN, M., 2008. 
Enfatiza-se que nas décadas de 1940 a 1950 a soja ainda não era cultivada no município como lavoura comercial. A partir de 1960, iniciou-se o plantio de soja em caráter experimental pela Fundação Estadual de Pesquisas Agropecuárias. No qüinqüênio de 1975 - 1980, a lavoura de soja, gradativamente, se expandiu em Júlio de Castilhos, desenvolvendo-se, paralelamente, a lavoura de trigo, a qual era, até então, o principal cultivo agrícola. Além disso, o transporte ferroviário nesse período, com vagões para grãos, favoreceu o escoamento da produção agrícola do município. No período compreendido entre os anos de 1985 e 1995 ocorre decréscimo na área de lavoura de soja, devido principalmente as oscilações no preço do grão no mercado internacional. No entanto, nesse período a produção aumentou, mediante o uso de tecnologias modernas, apesar do período de $95 \mathrm{ser}$ caracterizado por estiagens, as quais afetaram diretamente as áreas destinadas a lavoura da soja (Figura 2).

Além dos dados fornecidos pelos censos agropecuários do IBGE, buscaram-se dados da Fundação de Economia e Estatística (FEE), os quais disponibilizam informações mais atuais no que se refere à evolução da lavoura de soja em Júlio de Castilhos. Nessa perspectiva, pode-se dizer que nos últimos dez anos houve um aumento significativo e constante da área destinada a lavoura de soja. Este fato permite inferir que as áreas destinadas ao campo nativo estão cedendo espaço para essa lavoura. Destaca-se que a área plantada de soja tem aumentado gradativamente. No entanto, a sua produtividade, apresenta variações devido às oscilações climáticas, ocasionadas por períodos de estiagens ou excesso de chuvas. Observa-se, também, que a produtividade teve aumento significativo em relação aos períodos anteriores a 1995/96 (Figura 3).

Considerando as informações coletadas no trabalho de campo, os entrevistados ressaltaram que a soja era cultivada desde 1964 no município. Entretanto, o maior número de proprietários enfatizou que começaram a cultivar, essa leguminosa nos períodos de 1974-1983 e 1994-2003. O primeiro período coincide com o avanço dessa cultura, através do processo de 
modernização da agricultura no Estado gaúcho via uso de fertilizantes, agroquímicos e mecanização das lavouras. O processo de modernização iniciou no estado do Rio Grande do Sul com a Revolução Verde e através deste passou a utilizar, em larga escala, os agrotóxicos. No decorrer do tempo o aumento das pragas e o surgimento de novas doenças nas lavouras provocaram a ampliação no consumo de inseticidas, herbicidas entre outros agroquímicos. O uso de agrotóxicos nas lavouras de soja, trigo, milho, aveia, cevada, citricultura entre outras culturas é comum no município.

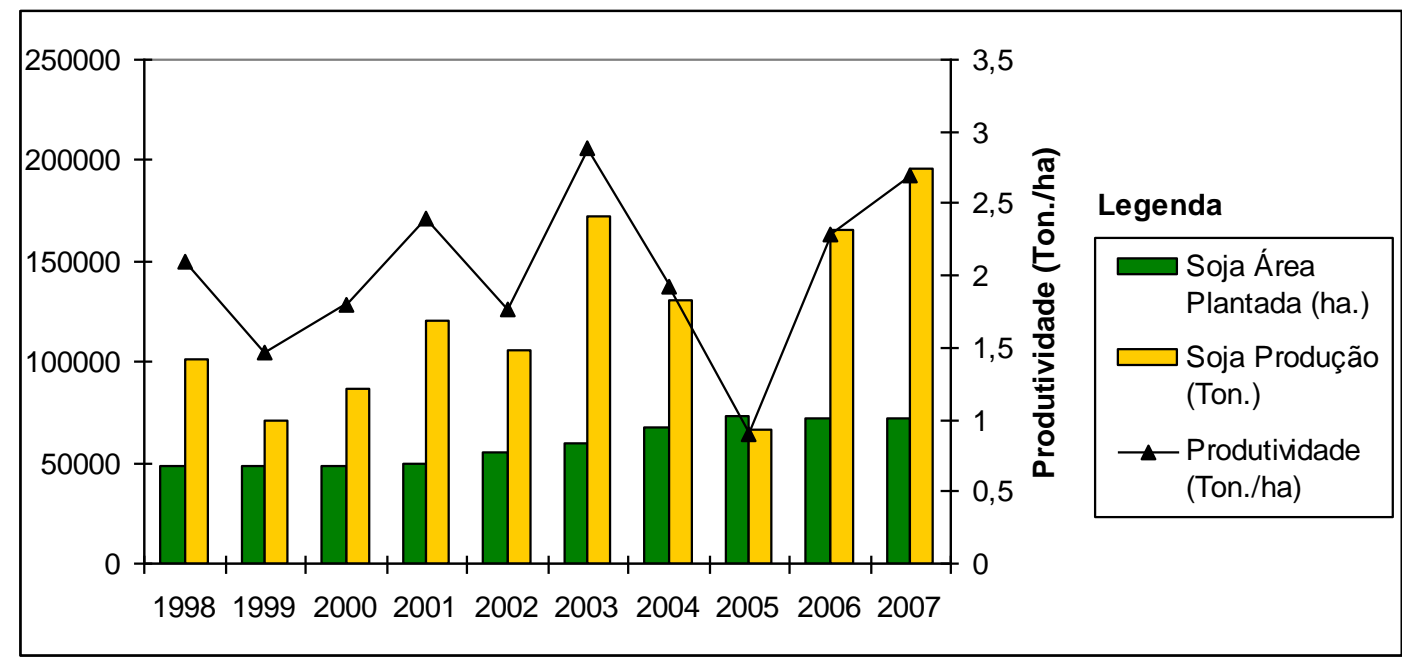

Figura 3 - Gráfico da evolução da área plantada e produção de soja de 1998 a 2007, em Júlio de Castilhos/RS.

Fonte: Banco de dados da FEE de 1998 a 2007.

Org.: CARGNIN, M., 2008.

O segundo período de 1994-2003 é caracterizado, pela expansão da soja decorrente da utilização, pelos proprietários, da técnica do plantio direto e o uso intenso da mecanização. Essa começou a ser difundida na década de 1980 e utilizada de forma intensiva a partir da década de 1990.

Vários fatores que motivaram os produtores rurais a iniciarem o plantio de soja, dentre eles, o mais citado está relacionado ao retorno financeiro rápido que esta atividade econômica proporciona apesar da grande vulnerabilidade as variações climáticas. Além disso, com a lavoura de soja é possível ter melhor 
aproveitamento econômico dos estabelecimentos agropecuários, pois a topografia do município disponibiliza terras aptas para a agricultura mecanizada. Essa oferta de terras apropriadas para o cultivo da soja aliados as perspectivas de mercado constituem a razão principal do aumento da área de soja no município.

Outros motivos citados para o plantio da soja estão relacionados a diversificação de atividades. Esta possibilita a rotação de culturas com objetivo de melhoramento do solo através da inserção de culturas específicas os quais aumentam a massa verde no solo, sendo que a mesma pode ser utilizada também na integração com a pecuária no período de entressafra.

Atrelado aos fatores físicos e os econômicos percebe-se que a atividade agrícola se torna mais viável no município. Acrescenta-se a esses a expansão da cultura de soja e a permanência da pecuária tradicional, são atividades que muitos produtores castilhenses herdaram e permaneceram devido às perspectivas de mercado e a visão expansionista da lavoura, uma vez que a soja destaca-se no Brasil tanto para o suprimento alimentar humano quanto para animal.

Salienta-se que para $56 \%$ dos entrevistados a soja transgênica foi fator decisivo na ampliação da área plantada com esta cultura, pois melhorou as condições de cultivo, bem como o controle dos invasores. Com o plantio de transgênicos, aliados a técnica do plantio direto houve redução de custos na lavoura, contribuindo para a expansão de áreas de cultivo.

Para os entrevistados que mencionaram o fato da soja transgênica não ter influenciado no aumento da área cultivada, suas opiniões convergem na direção do plantio direto, o qual tem direcionado a ampliação das áreas de lavoura, mediante a redução do manejo em comparação a lavoura cultivada no sistema convencional. Destacaram que com o plantio direto houve modificações na contratação de mão-de-obra na lavoura, pois com a redução do manejo com o solo e maior mecanização resultaram na diminuição de empregos.

No que se refere à área destinada para as culturas temporárias o maior número de produtores reservam de 50 a $100 \%$ do estabelecimento 
agropecuário para a lavoura comercial de soja. Salienta-se que da população entrevistada, 44 produtores rurais, tem como principal atividade econômica no período de verão a lavoura empresarial de soja. Nos meses de inverno, essas áreas são utilizadas para os cultivos de trigo, aveia/azevém, canola ou cevada.

Existem também no município, outras formas de utilização das terras. Nesse sentido, tem-se a presença de criadores de gado, embora em pequeno número, que se dedicam somente para a atividade pecuarista, deixando a agricultura para $\mathrm{o}$ arrendatário. Eles embora, em minoria, procuram alternativas para modernizar a atividade pecuarista através do melhoramento genético e da inserção de novas raças. A integração com a agricultura também faz parte do processo modernizante da pecuária. Nesse sentido, o ciclo da pecuária, foi acelerado, pois a redução de áreas para essa atividade diminuiu através da disponibilidade de arrendamentos sendo necessário que os pecuaristas procurassem técnicas modernas para compensar a cessão de áreas para agricultura via arrendamento.

Paralelamente a inserção da lavoura empresarial da soja, houve a busca por equipamentos mais modernos para acompanhar a evolução da modernização da agricultura. A expansão do mercado para a lavoura da soja tem permitido, aos agropecuaristas, modernizar a frota de seus equipamentos agrícolas, principalmente tratores e colheitadeiras através da adaptação dos maquinários usados com cabine ou através da compra de maquinários mais modernos.

Em Júlio de Castilhos o aumento do uso dos equipamentos agrícolas, pode ser percebido mediante a expansão da lavoura de soja. A frota de tratores sem cabine no município ainda é maior do que os equipados com cabine. A opção de equipamentos agrícolas mais modernos, por exemplo, a cabine com ar condicionado, está pautada na melhoria nas condições de trabalho no campo. Para as colheitadeiras agrícolas verifica-se que o processo de substituição dos modelos antigos por novos é mais rápido. Esse processo de modernização é visível, pois o número de colheitadeiras com cabine é aproximadamente três vezes maior que as sem cabine. 
A aquisição de colheitadeiras agrícolas com cabine foi possível devido às políticas de financiamentos e a possibilidade de inserção da soja no mercado nacional e internacional. Outras tecnologias modernas foram incorporadas nos trabalhos agrícolas como a cabine nos equipamentos para a pulverização de agrotóxicos necessários para a proteção da saúde do trabalhador rural, pois cada vez mais são utilizados os agroquímicos. Os equipamentos que os produtores rurais utilizam para a pulverização de agrotóxicos são: o trator sem cabine e jato em dezessete estabelecimentos; o trator com cabine e jato em seis; o autopropelido em dezoito e o avião agrícola em um estabelecimento.

Com o aumento das áreas de lavoura comercial foi necessária a ampliação e modernização dos maquinários agrícolas utilizados para o manejo das diferentes culturas. Além dessas modificações, as condições de trabalho no espaço rural também foram reestruturadas, sendo necessária a qualificação da mão-de-obra, para manejar equipamentos agrícolas mais sofisticados, como colheitadeiras computadorizadas, tratores com GPS entre outros. Muitos produtores rurais exigem do trabalhador a ser contratado o ensino médio completo e/ou com curso técnico em agropecuária. Tal fato é reflexo da modernização dos equipamentos agropecuários que os mesmos deverão utilizar no meio rural.

A lavoura empresarial além da modernização de maquinários agrícolas, os quais fornecem suporte diretamente nas atividades, exigiu também reestruturação na infra-estrutura para o armazenamento e transporte da produção. Para comportar a produção agrícola foi alterada a dinâmica rural com investimentos na construção e ampliação de silos nos próprios estabelecimentos.

A produção de grande parte dos estabelecimentos agropecuários é transportada para as cooperativas agrícolas de recebimento de grãos. Essas dispõem de infra-estrutura para armazenar grande parte da produção. Além do recebimento dos grãos, as cooperativas são responsáveis pelo armazenamento, comercialização e transporte dos mesmos. 
A combinação dos fatores relacionados à política agropecuária, econômicos e climáticos, favoreceu a maior integração da agricultura com a pecuária, pois através desse sistema há a possibilidade de minimizar os prejuízos derivados das variações do clima e das oscilações de mercado.

Para a maioria dos proprietários rurais essa integração oferece retorno financeiro mais garantido, pois a diversificação das atividades é uma alternativa para eles se manterem e/ou superarem as oscilações decorrentes dos mercados nacionais e internacionais. O retorno financeiro da pecuária é mais lento, ao contrário da agricultura temporária que a cada seis meses tem a possibilidade de entrada de recursos. Apesar de a atividade agrícola ser mais vulnerável as oscilações climáticas que a pecuária, por razões econômicas a agricultura detém maior importância, pois a mesma possibilita retornos econômicos mais rápidos ao produtor rural.

Nesse contexto, a falta de perspectivas de políticas de garantia de preços, a valorização da soja no grupo das commodities comercializadas no mercado internacional provocou acentuado aumento das lavouras de soja, as quais forçaram a diminuição das áreas utilizadas pela pecuária.

O consórcio entre agricultura e a pecuária é realizado por $96 \%$ dos produtores rurais entrevistados incluindo também os pecuaristas e arrendatários. Apenas $4 \%$ dos produtores permanecem apenas com a agricultura em seus estabelecimentos agropecuários. Afirmam que dessa forma a lavoura tem maior rentabilidade por não haver compactação do solo.

Nessa perspectiva, percebe-se que a organização do espaço rural segue a orientação econômica, ou seja, a escolha da atividade predominante (agricultura ou pecuária) será aquela que proporcionar maior rentabilidade em menor prazo. No município castilhense, a lavoura de soja apresenta-se como o principal agente dinamizador da economia local, pois os diversos segmentos de atividades do município desenvolvem-se em torno da economia agropecuária.

Destaca-se que os produtores rurais que optaram em não reduzir a área de campo permanecem com a atividade agrícola, entretanto, aumentaram o uso de tecnologias para maximizar a produção e, consequentemente, a rentabilidade econômica da lavoura. 
Para dar suporte ao desenvolvimento técnico no espaço agropecuário do município de Júlio de Castilhos, os produtores entrevistados afirmaram que todos têm acesso a assistência técnica para a agricultura e pecuária. Essa é disponibilizada pelas cooperativas ou empresas privadas através de serviços de veterinários, agrônomos, técnicos agrícolas entre outros profissionais que auxiliam no aperfeiçoamento das técnicas empregadas no processo produtivo. Para alguns não é necessário buscar assistência técnica, pois, o proprietário tem a formação profissional adequada para orientar as atividades no seu estabelecimento rural.

Dos cinquenta produtores entrevistados, trinta e seis consideram que a lavoura de soja continuará expandindo-se em áreas destinadas à pecuária. Alguns enfatizaram que haverá uma expansão limitada, devido aos condicionantes naturais que em determinadas áreas do município não possibilitam o uso da mecanização (TRABALHO DE CAMPO, 2008).

A expansão da agricultura, através da lavoura empresarial, em áreas de campo nativo é motivada pela valorização do grão no mercado internacional. Acredita-se que com o melhoramento e/ou aperfeiçoamento das técnicas e, a adesão gradativa da agricultura de precisão inicia-se o processo de verticalização da agricultura no município. Essa consiste na utilização de técnicas que proporcionam maior produtividade para a lavoura através da distribuição de fertilizantes e defensivos agrícolas.

Com base nos depoimentos dos produtores entrevistados constatou-se que eles têm perspectivas de ampliar as áreas destinadas para a lavoura da soja. As áreas de campo com relevo favorável para a agricultura poderão ser transformadas em lavouras, destinando a pecuária às áreas mais íngremes e com limitações para a agricultura mecanizada. Enfatiza-se também que a pecuária de leite está em expansão no município por concentrar grande quantidade de animais em menor área e por ser uma criação mais intensiva. Dessa forma, parte do efetivo da pecuária abrange a pecuária de leite o que tem refletido positivamente para o desenvolvimento econômico do município.

Alguns produtores destacaram que as áreas de expansão da lavoura de soja já estão se esgotando no município. Tal fato implicará na estabilização da 
área plantada, mas com possibilidades de investimentos que visem o aumento da produtividade. Com a cedencia das áreas de campo para a lavoura de soja houve aumento da oferta de pastagem. Assim, a pecuária também busca novas alternativas modernizando-se e reduzindo o tempo para o abate. Se por um lado a pecuária de corte perdeu áreas de campo, por outro, se tornou mais intensiva beneficiando-se também da lavoura em períodos de menor disponibilidade de pasto no campo nativo.

Pode-se dizer, então, que as modificações na agropecuária castilhense são decorrentes da dinâmica da economia nacional e internacional que movimentam o agronegócio gaúcho. Para atender as novas demandas do mercado reestruturam-se as cadeias produtivas antigas ou inserem-se novas para fornecer fluidez à economia. A tradicional atividade pecuarista modernizou-se e busca a competitividade, forçada pela agricultura empresarial, a qual pressionou a diminuição das áreas de campo. A agricultura, através da lavoura empresarial da soja, desenvolve-se através de alto padrão tecnológico sendo um das exigências ao produtor rural, para o mesmo, se manter na atividade e acompanhar a concorrência no agronegócio.

Os produtores acreditam que não haverá mudança significativa de tipos de cultivos diferentes em relação às culturas tradicionais (soja, trigo e milho), mas a utilização de novas variedades das culturas agrícolas já existentes aliado ao uso de técnicas mais modernas visando o aumento da produtividade.

Desse modo, a reorganização do espaço agropecuário segue a orientação econômica, impulsionando o desenvolvimento das atividades rurais, através da maior ou menor valorização comercial, das mesmas, no mercado local, regional, nacional e internacional. No entanto, os aspectos culturais locais interferem impedindo que atividades tradicionais desapareçam, como a pecuária, que se inseriu na gênese de formação do estado gaúcho, principalmente na Metade Sul, expandindo-se para a região central até municípios como Júlio de Castilhos, onde tornou-se tradicional. Por conseguinte, podemos dizer que, a tradição atrela-se a novas atividades que se inserem no espaço agropecuário local, dinamizando a economia e aperfeiçoando as atividades já existentes. 


\section{CONSIDERAÇÕES FINAIS}

O espaço rural de Júlio de Castilhos desde a sua gênese apresenta como característica marcante, na sua estrutura fundiária, os grandes estabelecimentos agropecuários, herança das sesmarias, tendo como atividade primordial a pecuária. Da emancipação política até a atualidade, o município passou por significativas reorganizações espaciais, tanto no que se refere ao tamanho dos estabelecimentos rurais, quanto pelo tipo de atividades praticadas nos mesmos.

A estrutura das atividades pecuaristas e agrícolas, as relações de trabalho, tendo por base a demanda de mão-de-obra temporária e permanente e os instrumentos de trabalho, foram agregadas em bases produtivas e técnicas mais consentâneas a realidade. As mesmas foram assimiladas, no decorrer do tempo, atendendo as culturas com bases empresariais impostas pelas exigências do mercado e do atual período técnico-científico-informacional que vivemos. Assim, percebe-se, no município, uma dicotomia produtiva (pecuária $x$ agricultura), reflexo das distintas incorporações técnicas, na qual a lavoura empresarial da soja é o exemplo mais expressivo nessa unidade territorial.

É importante destacar que as transformações, no setor produtivo de Júlio de Castilhos, ocorreram em parte, em consequência do fechamento da fronteira agrícola do Rio Grande do Sul, a partir da década de 1950. Tal fato foi responsável por novos arranjos produtivos no estado gaúcho, pois a falta de oferta de terras, no mercado, pressionou as áreas de pecuária a cederem seus espaços às lavouras empresariais, no caso específico dessa pesquisa, a da soja.

Salienta-se que, em Júlio de Castilhos, tem-se, por um lado, a diminuição do efetivo da pecuária e, por outro, o aumento gradativo das áreas destinadas à agricultura empresarial. Essas transformações no espaço rural local ocorreram de forma mais acentuada, a partir da década de 1990, como 
demonstra os dois últimos censos do IBGE de 1995/96 e 2006, respectivamente.

A lavoura comercial de soja, em Júlio de Castilhos, teve início na década de 1960 em caráter experimental e, gradativamente, expandiu-se a partir de 1975, resultante da demanda e da valorização do grão no grupo das commodities brasileiras. Paralelamente, sua importância, nesse momento, também está ligada ao binômio "trigo-soja" que se constituía, no estado gaúcho, como a principal atividade econômica. Dessa forma, a agricultura se expandiu através da lavoura temporária em moldes empresariais com a sua produção direcionada para o mercado regional, nacional e internacional.

É perceptível, no município, a mudança na paisagem rural, pois algumas fazendas com tradição em pecuária de corte preservam o nome, mas, no entanto, grande parte da sua área é destinada para a lavoura da soja em detrimento da pecuária. Assim, a maioria dos campos nativos aparece como "ilhas de pecuária" se comparadas à produção agrícola. Pode-se considerar que o pecuarista de Júlio de Castilhos, na atualidade, deixou de ser criador de matrizes para a pecuária de corte para ser invernador, ou seja, grande parte da pecuária bovina de corte, presente na maioria dos estabelecimentos é proveniente de outros municípios.

Esse novo redesenho da paisagem rural do município pode ser percebido pela expansão da agricultura empresarial a qual possibilitou a reestruturação e o fortalecimento da economia local visando inserir o município no desenvolvimento regional. É importante salientar que houve valorização da terra em consequência da expansão da cadeia produtiva da soja.

Pode-se afirmar também que as transformações socioespaciais, ocorridas no município, acompanham as alterações do seu espaço rural. Como se pode perceber a lavoura de soja gerou nova dinâmica no espaço local reorganizando-o no decorrer do tempo.

Nesse contexto, pode-se destacar como principal agente da reorganização do espaço produtivo local o agronegócio. Esse organiza o complexo agroindustrial da soja, através dos produtores rurais, da indústria a montante e a jusante, do sistema financeiro, das cooperativas e das empresas 
agropecuárias privadas, que através de suas interações são as responsáveis por significativas mudanças econômicas, sociais e espaciais nessa unidade territorial. Salienta-se também que a inserção da cultura da soja, no município, foi responsável por uma reestruturação do espaço urbano, pois ambos estão interligados. Ou seja, o aumento de renda gerado no setor rural implica, na sua maioria em investimentos no urbano.

Enfatiza-se que desde a inserção da cultura da soja, no município ocorreu a reestruturação no setor rural, as quais são perceptíveis, na atualidade, principalmente através do processo de despecuarização espacial com crescimento significativo da agricultura tecnificada através da lavoura empresarial via complexo da soja.

\section{REFERÊNCIAS}

BELLINASO, Luciana. Análise de mercado Complexo da soja. 2002, $43 \mathrm{f}$. Monografia (Especialização em Gestão Estratégica Empresarial) Universidade Federal de Santa Maria, Santa Maria, 2002.

BEZZI, Meri Lourdes. São Borja - Transformações no Espaço Agropecuário: O Processo de Despecuarização. 1985. 222f. Dissertação (Mestrado em Organização do Espaço) - Universidade Estadual Paulista, Rio Claro, 1985.

BENETTI, Maria Domingues. Reestruturação do agronegócio no Brasil e no Rio Grande do Sul nos anos 90: Concentração, centralização e desnacionalização do capital. In: Secretaria da Coordenação e do Planejamento. Economia gaúcha e reestruturação nos anos 90. Porto Alegre: FEE, 2000.

BOMBARDIERI, Gilberto. A Nova "Revolução Verde" da agricultura implicações político-sociais e ambientais no cultivo de plantas geneticamente modificadas. 2000. 108f. Dissertação (Mestrado em Extensão Rural). Universidade Federal de Santa Maria, Santa Maria, 2000.

BRUM, Jacob Argemiro. Modernização da agricultura: trigo e soja. ljuí: Vozes, 1988.

CARRION JÚNIOR, Francisco M. RS: Política Econômica e Alternativas. Porto Alegre: Mercado Aberto, 1981.

CONCEIÇÃO, Otavio Augusto Camargo. A Expansão da Soja no Rio Grande do Sul (1950 - 75). Porto Alegre: FEE, 1984.

EMPRESA BRASILEIRA DE PLANEJAMENTO AGROPECUÁRIO - CLIMA TEMPERADO. Indicações técnicas para a cultura da soja no Rio Grande do Sul e em Santa Catarina 2006/2007. Pelotas: EMBRAPA Clima 
Temperado, 2006, Disponível em: < http://www.cnpso.embrapa.br/index.php> Acesso em: 29 Jan. 2008.

FUNDAÇÃO DE ECONOMIA E ESTATÍSTICA. 25 anos de economia gaúcha: A agricultura do Rio Grande do Sul. Porto Alegre: Ed. da FEE, v. 3,1978.

. A mecanização da agricultura do Rio Grande do Sul 1920 - 75. Porto Alegre: FEE, 1979.

HEIDRICH, Álvaro Luiz. Além do latifúndio: Geografia do interesse econômico gaúcho. Porto Alegre: Ed. da UFRGS, 2000.

HESPANHOL, Antônio Nivaldo. Agricultura, desenvolvimento e sustentabilidade. In: MARAFON, Gláucio José; RUA, João; Ribeiro, Miguel Ângelo. Abordagens teórico-metodológicas em geografia agrária. Rio de Janeiro: Ed. da UERJ. 2007, p.179 - 198.

MAZZALI, Leonel. 0 processo recente de reorganização agroindustrial: Do complexo à organização "em rede". São Paulo: Ed. da UNESP, 2000. (Coleção Prismas/PROPP).

PESAVENTO, Sandra Jatahy. RS: A economia \& poder nos anos 30. Porto Alegre: Mercado Aberto, 1980. (Série Documenta, 7). 